\title{
A global tool for the architectural and environmental quality of materials integrated into the architectural design process
}

\author{
L. Fernandez ${ }^{1,2}$, F. Bonneaud ${ }^{1} \&$ S. Lorente ${ }^{2}$ \\ ${ }^{1}$ Laboratoire de Recherche Architecturale, Groupe de Recherche \\ Environnement et Conception Architecturale et Urbaine, \\ Ecole d'Architecture de Toulouse, France \\ ${ }^{2}$ Laboratoire Matériaux et Durabilité des Constructions, \\ Institut National des Sciences Appliquées de Toulouse, France
}

\begin{abstract}
In the very first phase of a design project the architect must choose both the materials and implementation processes. We propose in this work a global and cross-cutting design tool, "MaTerre'iO", to help the architect to make his choices based on environmental quality concerns. Firstly, we present the initial context of our work. Tools such as ours are still recent in the area of environmental architecture, and are often complex because they require a high level of expertise to be used correctly. This is why the objective of "MaTerre'iO" is to offer pragmatic information on the quality of materials starting at the beginning of the very first draft, in order to guide the various actors of the building project throughout the process of design. Then, we explain the principles of "MaTerre'iO": 1. to provide a global outlook, which is particularly needed in architecture; 2. to respect the design process phases (evolution of the nature of the requested input data); 3 . to provide an easier comprehension to non-expert eyes on the environmental and technical aspects. A multicriterion grid provides a comprehensive view of the project. Next, we develop two of the criteria of our multicriterion analysis grid, and illustrate them through one example: (i) the physical pollution that governs the impact on the environment, on health and on the quantities of waste, and (ii) the footprint of energy consumption and resources consumption. The multicriterion analysis grid allows a multidisciplinary approach. It is based on three approaches: the global approach for architects, the awareness approach for the participating actors and the expert
\end{abstract}


approach for engineers. Finally, we present its novelty and advantages, particularly its interdisciplinary and ability to ease the exchanges between the different actors of an architectural design process.

Keywords: environmental quality, tool, materials, architecture, footprint of energy consumption, physical pollution, multicriterion analysis grid.

\section{Introduction}

This work presents how the environmental quality of materials can impact the process of architectural design. In the traditional way of designing a new architectural project, the environmental impact of the components and of their assembly is approached in the last phases, when it is often too late to change the earlier choices. The alternative is to account for, or at least to be aware of, the environmental quality of the materials at the very first stages of the design.

We focus in this paper on numerical tools related to the choice of materials and the processes of implementation. Such tools are very recent in the domain of environmental architecture compared to those dedicated to energetic and comfort. We present first a brief review on the different kinds of tools available today, focusing more specifically on their ability to be integrated into the design process. Next the numerical tool developed in the frame of our research, "MaTerre' $\mathrm{iO}$ ", is presented. It consists on a multicriterion analysis grid that we illustrate through two criteria, before concluding on the advantages and the limits of "MaTerre'iO". The two criteria that we chose in our multicriterion analysis grid are the physical pollution and the footprint of energy consumption.

\section{Initial context: ability of current tools to be integrated into the design process}

The tools related to the choice of materials and the processes of implementation have changed dramatically these past years, and particularly computer softwares. Three main families can be distinguished [1]. They are tools dedicated to helping the designers to learn more on the impact the materials and their implementation may have on an architectural project:

- database: this type of tool is widespread, they serve the quantification of the impact and aesthetic qualities of materials.

- environmental impact tools: the main objective of such tools is to help to exploit in a more easy way the data contained in the databases. They are not very much in use within the architectural community.

- tools combining materials and other environmental issues: this type of tool is rare.

Level of expertise:

The use of these tools requires a high level of expertise. Indeed the available data refer to specific knowledge such as technical data, mechanical details, health impact, environmental approach...The tools specialized in for example lighting, acoustics, heat transfer through buildings, are destined to experts of each field. 
As a consequence information on the environmental impact of a material because of its interdisciplinarity is too complex for a non-expert. Because of that, they cannot be accounted for during the choices of design.

Materials data collection:

Today, data such as physical aspects of materials or constructive systems are relatively well-known and reliable for most of the studied criterion. As far as environmental aspects are concerned, the user must be extremely careful because the available data are on a self-declared basis. Therefore, experience and distance are required. In addition, economic aspects of the materials are difficult to account for. They are subject to exogenous factors in the sense that they depend on the geographical location of the construction, on the fluctuation of raw material, inflation, etc. Moreover, the collection of materials data raises the question of their regular update, of their homogeneity and objectivity. In sum, databases nowadays are very shallow and the information on their origin incomplete.

Integration of the design process phases:

The available tools require one to know the precise quantities of materials that will be used. In the situation of an architectural project, this means to be in an advanced phase of the design process, in order to be able to characterize the architectural proposal. Whereas today, the designer becomes interested in the material choices in the first phases of the project. Therefore it is difficult to use these tools.

It is important to notice that today, in order to be in phase with the different design process stages, some tools reason in terms of length of façade rather than in surface of materials. This tendency seems to be interesting because it allows a simplification of the input data requested to the designers.

A more global view is needed in architecture:

As far as the environmental quality of the materials is concerned, most of today knowledge and most of the tools focus on the energy footprint or on the carbon footprint. As far as the domain of architecture is concerned, it is essential to have a more global view when it comes to the choice of materials. In order to answer the designers' expectations, without minimizing the architectural quality, the process of architectural project must integrate a multidisciplinary approach.

The objective of "MaTerre'iO" tool is to inform the designer on the environmental impact of the choices of materials and processes of implementation. We focus on the different needs that we mentioned in order to offer pragmatic information on the quality of materials at the beginning of the very first draft, in order to guide the various actors of the building project throughout the process of design.

\section{Principles of "MaTerre'iO"}

MaTerre'iO tool is the result of the collaboration between a French environmental architecture laboratory and engineering research laboratory. The 
benefits of the exchanges come from the relationship between these two complementary professions.

\subsection{The different principles of MaTerre'iO}

The different principles that are in "MaTerre'iO" were derived from the particularities of the existing tools that we mentioned before, and from the discussions we had with specialists in environmental architecture and designers. We learnt from the specialists about the role of the different tools, their advantages and their limits. The designers informed us on the approach of the architectural project and especially on the choice of materials and processes of implementation.

\subsubsection{A global view}

In a design phase, designers handle the question of materials by combining simultaneously the constructive, environmental, aesthetic, economical, energetic and normative aspects of materials. To design means to account for different knowledge. We thought it would be interesting to reduce the number of architectural and environmental markers related to materials and devices of construction in order to be more global, pragmatic and efficient. Following a broad review on this topic, we gradually set up a multicriterion analysis grid. This grid is a structure of 3 levels. To date, the global vision level on the quality of materials is based on 7 criterions.

\subsubsection{Respecting the design process phases and providing an easy comprehension to non-expert eyes}

The question of materials and processes of implementation arises throughout the duration of the architectural project, but in various ways (Figure 1). Crucial choices are made during the very first phases of the project, whatever the project, the site and the work method used by the designers. In order to gain in

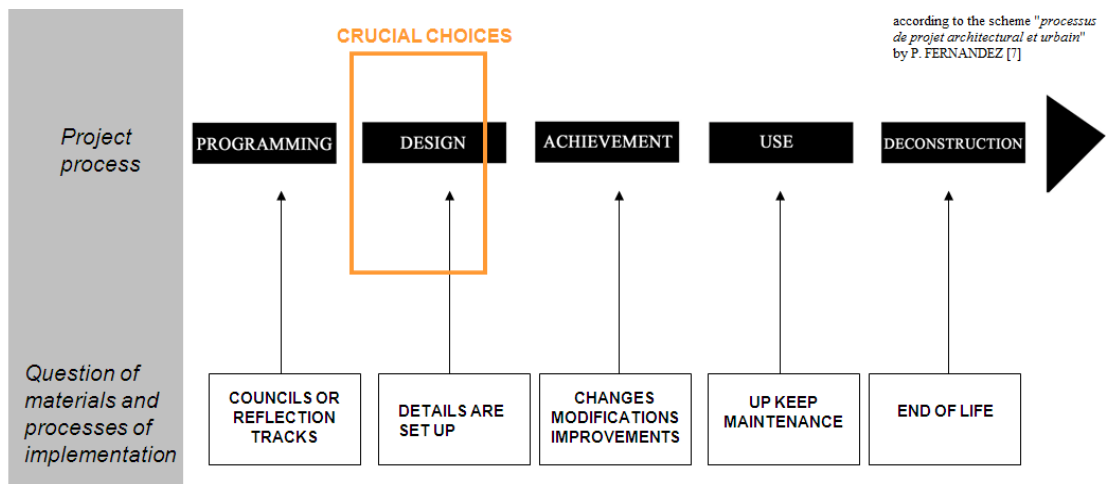

Figure 1: Design process phases and the question of materials and processes of implementation. 
effectiveness, it is important to concentrate on this phase of the draft when developing future tools. This will allow easier optimizations during later phases of the project [2]. In addition, to be efficient and easy to use, the tool must be running fast and need to propose a convivial interface to integrate into the process of design.

\subsubsection{Nature of the requested input data}

The input data must be in adequateness with the needs of the designer in the first phases of the architectural design process. This is the reason why the proposed input data must be simple and in small numbers.

In "MaTerre'iO" tool, we propose only four input data (Figure 2):

- The city where the project will be built (for the climatic conditions)

- A simplified 3D drawing to see the morphology of the buildings, the volumes.

- The orientation

- The type of architecture devices: foundations, structures, partitions, envelope, openings, roofs. We propose to reason on materials devices and not on materials only.

The main idea is to compare the environmental impacts of the various choices at the very beginning of the draft, without going into any building detail.

\subsubsection{Gathering of data on the environmental impacts of materials}

In order to feed our tool, we set up a materials database, the most homogeneous and reliable possible. Today, our database centralizes and classifies all the

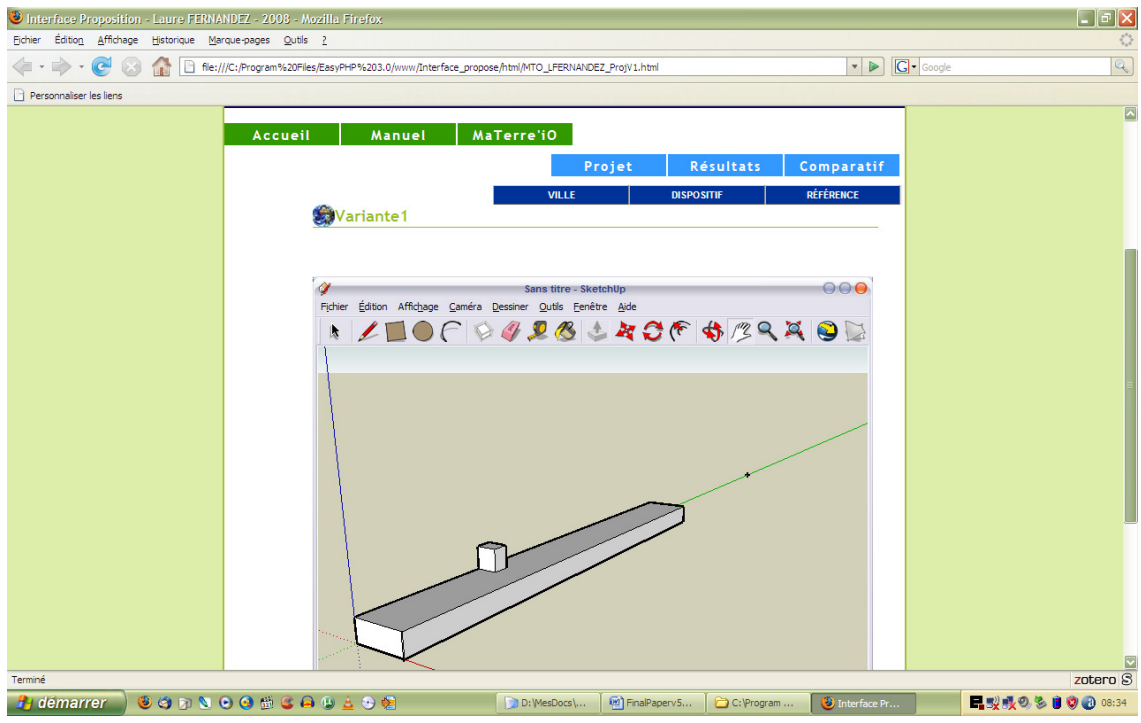

Figure 2: $\quad$ Example of input data in the MaTerre'iO tool. 
characteristics of materials. It amalgamates physical, technical, environmental, economical and aesthetic data. It is as exhaustive as possible. It gathers information coming from various sources: Ademe, CSTB, inies, izuba, KBOB, Wufi, etc [3].

It is worth noticing that the environmental data harvesting is long and difficult mostly because such needs are recent or some parameters are unknown.

\subsection{Multicriterion analysis grid}

We developed in this work a multicriterion analysis grid in order to reduce the number of architectural and environmental markers related to materials and devices of construction. After a broad research on the subject, we set up a multicriterion analysis grid in 3 levels based on a tree structure.

\subsubsection{Multicriterion analysis grid elaboration}

At first, we were looking for a method that takes into account different criterion, without reducing at one [4,5]. The objective was to find an acceptable solution in an environment where the appreciation criterions are complex and plentiful.

A multicriterion analysis is better than a monocriterion one because it accounts for many criterions often conflicting. The multicriterion analysis seeks for compromises rather than an optimum result.

We developed a hierarchical structure with a top-down approach. The grid had to be exhaustive, irredundant, coherent, independent and readable. The objective of the multicriterion analysis grid was to propose a global glance on many criterions of materials and processes of implementation at the beginning of the draft phase. It was developed from an exhaustive bibliography on environmental knowledge on materials. Many fields were studied: the impact of the materials on health, on biodiversity, the life cycle of materials, their aesthetic cultural and technical aspects, their energy consumption, wastes....

Moreover, we used the results of a previous inquiry to complete our structure: first, we discussed with experts on the tools function in the design process. Second, we discussed with architects about their work method on the question of materials and processes of implementation.

\subsubsection{Multicriterion analysis grid}

To date, we reduced the global vision on the quality of materials and processes of implementation into 7 criterions (Figure 3). Each of the 7 criterions (global approach), is declined under different sub-criterions: indicators (awareness approach) which are declined in markers (expert approach) [6].

We propose different results according to the user's level of knowledge and to his comprehension level. The results at the levels of global approach and awareness approach are explained with indicators: very good - good - medium bad - very bad. This makes the comprehension of the results easy. On another hand, the results at the level of expert approach are explained as precisely as possible through numbers. In sum, according to the user's level of expertise, it is possible to benefit from an increasingly precise and complete approach. 
GLOBAL APPROACH

First degree

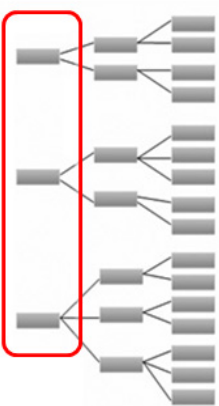

criterions
AWARENESS APPROACH

Second degree

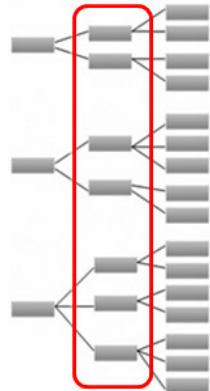

indicators
EXPERT APPROACH

Third degree

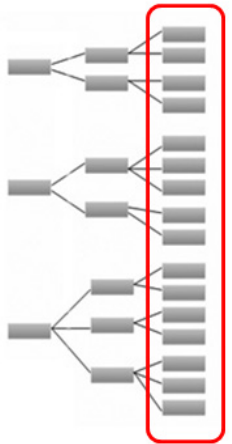

markers

Figure 3: $\quad$ Multicriterion analysis grid, different approaches.

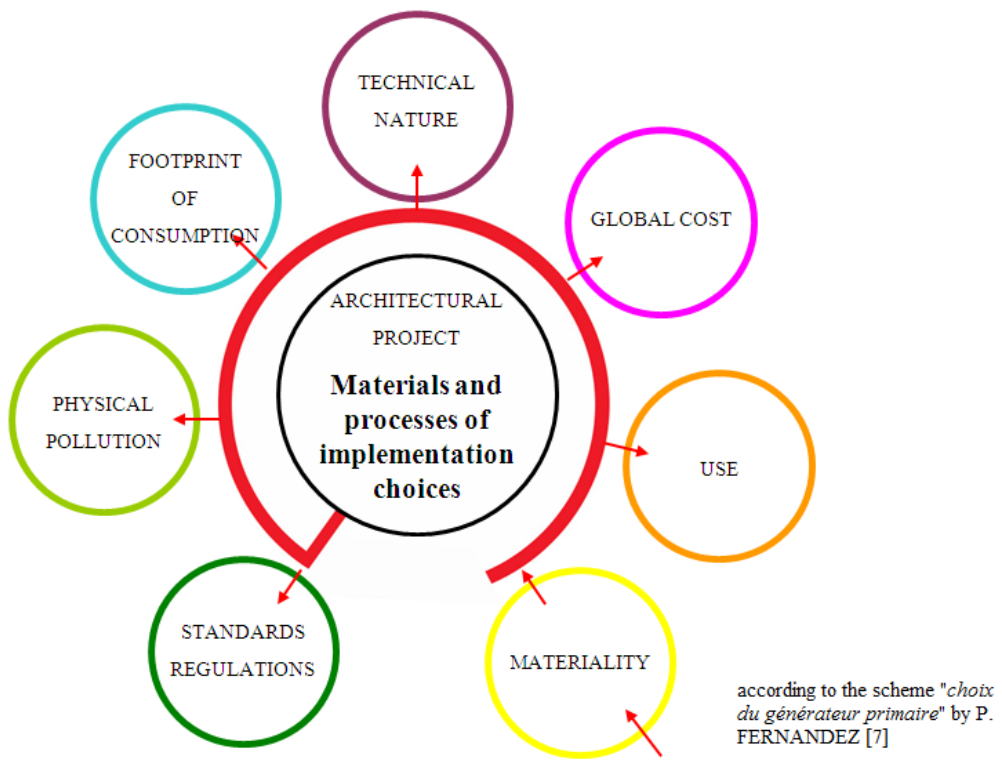

Figure 4: The seven criterions of the multicriterion analysis grid. 
Even though it is necessary to study each criterion, the needs are different according to the context; designers, project, etc [7]. For example, the architect may be interest in the usefulness of a material before its physical pollution on the environment.

The seven criterions (Figure 4) are physical pollution, footprint of energy consumption, materiality, use, global cost, technical nature, and standards regulations.

These criterions offer a global vision on the environmental questions of materials and processes of implementation for designers.

\subsection{Illustration of the tool: Galopin's house in Seniergues (France)}

To illustrate our tool, the "Galopin's house" project was chosen. This project is known as a great project about environmental architecture. It was presented in several books, as for example the book from Dominique Gauzin-Müller "25 maisons écologiques" [8].

The main features of the Galopin's house are:

- Orientation

- Implantation: semi-buried

- Choice of materials : local stone

- $\quad$ Ratio between windows and façades

- $\quad$ Room organization in the building

We compared two architectural solutions from the point of view of the choice of materials and processes of implementation. The first solution is the solution chosen by the Gouwy Grima and Rames architecture agency. The architects used preferentially local stone for the envelope of the house with an approach (or thought process) that happened to be environmental friendly. Second, we proposed a more classical solution by using concrete and coating for the envelope of the house.

Our tool MaTerre'iO allows comparing the different solutions in order to improve the designers' choices.

\section{Two criterion of our multicriterion analysis grid}

In this work we chose to develop two criterions based on the following requirements:

- $\quad$ They concern the environmental qualities of materials,

- They are almost unknown to designers

- $\quad$ They correspond to the fields studied in our laboratories

We chose the criterions of physical pollution and footprint of energy and resources consumption. The data were found in several sources. Mainly the Inies database was used. This database stores FDES forms (environmental and health declaration form) [9]. 


\subsection{Physical pollution}

The physical pollution is the introduction in the environment of substances up to a level that their effects become harmful to human health, environment and/or climate.

The physical pollution criterion is declined into three indicators: environmental impacts, human impacts and waste impacts.

The environmental impact indicator is declined itself into several markers such as:

- climatic modification marker: it estimates the materials contribution in the greenhouse gases emission in the atmosphere. This marker amalgamates all the greenhouse gases emissions.

- atmospheric acidification marker: it takes into account the materials compounds which are transforming into acid. Note that these markers are hazardous for fauna and flora.

- air, water and soil pollution markers: they estimate the toxic and ecotoxic impacts of emissions in the air, water and soil. These markers amalgamate principally organic compound and metal.

- ozone layer destruction marker: it estimates the material contribution in the ozone layer destruction.

- photochemical ozone formation marker: it estimates the emissions contribution in ozone formation.

The human impact indicator is declined into five markers:

- moisture and microorganism marker: it estimates the materials sensitivity for moisture and microorganism development.

- fibers and particle produce marker: it estimates the fibers and particle emissions. Hazardous emissions depend on its physic-chemical characteristics and persistence in biologic tissues.

- VOCs marker: it estimates volatile organic compounds emissions.

- radioactive emissions marker: it estimates the quantity of radioactive emissions of materials.

- cancer risk marker: it classifies the materials according to cancer risk.

The waste impact indicator is declined into five markers:

- value waste marker: it accounts for all the wastes for which valorization is possible.

- hazardous, not hazardous, inert and radioactive wastes markers: they estimate the volume of waste to be abandoned. The waste classification is hazardous, not hazardous, inert and radioactive wastes.

\subsection{The footprint of energy consumption and resources consumption}

The footprint of energy consumption and resources consumption is the impact on all the resources: energy, consumption, etc. This criterion is declined into two indicators: footprint of energy consumption and resources consumption. These two indicators are declined into five markers: 
For the footprint of energy consumption, the markers are:

- renewable energy marker: this marker takes into account the cultivated, naturally renewable or regenerable resources.

- non renewable energy marker: it estimates the fixed amount of resources existing on earth which cannot be renewed at human time scale.

For the energy consumption, the markers are:

- resources exhaustion marker: this marker takes into account the both resources consumption: energetic or non energetic resource, excepted water.

- water consumption marker: it estimates the water consumptions of the material during their entire life cycle

- territory consumption marker: this marker is difficult to evaluate. This is why we estimate only the area consumption by the architectural project.

\subsection{Criterions, indicators and markers work method}

In order to be in adequacy with the expectations of our multicriterion analysis grid, we present the results on our markers differently depending on the approaches. Thus the results on the expert approach are the sum of all the data on the materials used in the architectural project. The results are expressed in numbers. The awareness and global approaches results follow the expert results. We created boundary markers to explain the results by means of the following indicators: very good - good - medium - bad - very bad. Each markers and indicators are weighted according to their importance. The level-headedness depends on the existing knowledge.

\section{Conclusion: advantages and limits of our research work}

We proposed a tool which is compliant with the architectural process: a global view (multicriterion analysis grid), the respect of the design process phases, a tool providing an easy comprehension to non-expert eyes, an evolution of the nature of the requested input data... The exhaustive data base on environmental data about materials allows thinking in terms of device or assembly of materials rather than material itself in order to follow the process of design in the architectural project.

MaTerre'iO tool is innovative and we believe it is in adequacy with the designers expectations. To our knowledge, it is the only tool that is proposing simplified data on the environmental questions of materials and processes of implementation.

Difficulties and limits of this work are as follows:

- data access, mainly for some material families,

- data access, mainly for all material devices, 
- $\quad$ objectiveness in weighting the indicators: these weightings are based on our readings and discussions with experts. We believe that they need more scientific validation as for example in the case of not cancer risk marker [10].

\section{References}

[1] Fernandez L., Bonneaud F., \& Lorente S., Environmental quality of materials: software tools of pertaining to architectural quality, $25^{\text {th }}$ Conference on Passive and Low ENERGY Architecture, Dublin, $22^{\text {nd }}$ to $24^{\text {th }}$ October 2008 .

[2] Bornarel A., Qualité environnementale des bâtiments - Manuel à l'usage de la maîtrise d'ouvrage et des acteurs du bâtiment, Ademe edition, France, 2003.

[3] http://www.cstb.fr

[4] Schärlig A., Décider sur plusieurs critères - Panorama de l'aide à la décision multicritère, Presses polytechniques et universitaires romandes, Lausanne, 1985.

[5] Roy B., Méthodologie Multicritère d'Aide à la Décision, edition Economica, Paris, 1985.

[6] GRECO (EAT) \& EAPB, SAGACités: vers un Système d'Aide à la Gestion des Ambiances urbaines, rapport d'étude, France, 2002.

[7] Fernandez P., De l'architecture bioclimatique au développement urbain durable, Habilitation à diriger des recherches, Institut National Polytechnique de Toulouse, France, 2007.

[8] Gauzin-Müller Dominique, 25 maisons écologiques, edition Moniteur, Paris, 2006.

[9] http://www.inies.fr

[10] Déoux S. \& P., Le guide de l'habitat sain - les effets sur la santé de chaque éléments $d u$ bâtiment, Medieco editions, deuxième édition revue et augmentée, Andorre, 2004. 